\title{
Ethical aspects of legal abortion from the viewpoint of pregnant women referring to the forensic medicine center in Iran
}

\section{Mahboubeh Valiani}

Assistant Professor, Department of Midwifery and Reproductive Health, Isfahan University of Medical

Sciences, Isfahan.

\section{Gita Montazery}

General Practitioner, Isfahan Forensic Medicine, Isfahan

\section{Ali Mohammad Sabzghabaee}

Professor of Pharmacotherapy, Isfahan Clinical Toxicology Research Center, Isfahan

Somayeh Hamdavipour ( $\nabla$ s.hamdavipour@gmail.com )

MSc student of midwifery, Isfahan University of Medical Sciences, Isfahan

\section{Research Article}

Keywords: Medical ethics, Ethics, Morals, Pregnant women, viewpoint, Abortion, Iran

Posted Date: December 14th, 2020

DOl: https://doi.org/10.21203/rs.3.rs-117623/v1

License: (9) This work is licensed under a Creative Commons Attribution 4.0 International License.

Read Full License 


\title{
Ethical aspects of legal abortion from the viewpoint of pregnant women referring to the forensic medicine center in Iran
}

Mahboubeh Valiani ${ }^{1}$, Gita Montazery ${ }^{2}$, Ali Mohammad Sabzghabaee ${ }^{3}$ and Somayeh Hamdavipour ${ }^{4 *}$

\author{
Author Details \\ ${ }^{1}$ Assistant Professor, Department of Midwifery and Reproductive Health, Isfahan University \\ of Medical Sciences, Isfahan, Iran. \\ ${ }^{2}$ General Practitioner, Isfahan Forensic Medicine, Isfahan, Iran. \\ ${ }^{3}$ Professor of Pharmacotherapy, Isfahan Clinical Toxicology Research Center, Isfahan, Iran. \\ ${ }^{4} \mathrm{MSc}$ student of midwifery, Isfahan University of Medical Sciences, Isfahan, Iran. \\ (Corresponding Author). E-mail: s.hamdavipour@gmail.com
}

\begin{abstract}
Background: Abortion has always been one of the most challenging issues in societies. Women's decision for having a legal abortion has always been influenced by factors such as their spouse, family, society, culture and religious beliefs. Thus, this study aimed to investigate the ethical aspects of legal abortion from pregnant women's viewpoints, referring to Iran's forensic medicine center.
\end{abstract}

Methods: This is a descriptive-analytical study conducted in 2019. The research samples consisted of pregnant women referring to forensic medicine in Isfahan for obtaining legal abortion permission. Using a convenience sampling method, 229 subjects were selected. The data collection tool was a researcher-made questionnaire. The obtained data were analyzed using descriptive and inferential statistical methods.

Results: In the present study, the highest and lowest mean score of ethical aspects belonged to the variables of autonomy $(36.20 \pm 3.01)$ and justice $(17.24 \pm 2.45)$, respectively. The mean scores of the ethical aspects of legal abortion were not significantly different between mothers with a wanted or unwanted pregnancy.

Conclusion: women's autonomy in having a legal abortion had the highest score, while the lowest score belonged to justice in legal abortion. 
Keywords: Medical ethics, Ethics, Morals, Pregnant women, viewpoint, Abortion, Iran

\section{Background}

In 2018, 9,700 Iranian women received permission for medical abortion [1]. Abortion is defined as the termination of pregnancy before the 20th week of pregnancy or the termination of it when the fetus has a lower than 500 grams weight and cannot live outside the uterus. Currently, the most prevalent indication for medical abortion is to prevent a newborn's birth with a significant anatomical, metabolic, or intellectual disorder [2].

Some issues, such as abortion and the physician-patient relationship, have a long history in medical ethics, considered in ancient medical texts [3]. To make an ethical decision about abortion, several issues have to be considered, which include the intentions of the mother (pregnant woman), the interests and rights of the fetus such as its right to live, the stage of fetal development, and the abortion-related ethical assessments [4]. Four fundamental principles are used in Western countries as a guide for making moral decisions which are 1) autonomy, 2) beneficence, 3) non-maleficence, and 4) justice [5].

In the study of Svenaeus, it has been argued that the idea of patient autonomy has provided every woman with the right to legal abortion as part of a bioethics program and other political movements [6]. Svenaeus also argues that the birth of a baby with severe physical disabilities such as anencephaly, Edwards syndrome, muscular dystrophy, and cystic fibrosis, which make the baby suffer intensely and have a short life, seems irresponsible and immoral [6].

McCallum et al. showed that discrimination against women is an integral part of the structure, organization, and culture of hospitals, which is not solely caused by healthcare professionals' actions [7].

One of the criteria for respecting individuals' autonomy is confidentiality; that is, the protection of the patient's secrets, which is important both morally and legally [4]. In Zulu et al's study, conducted to examine the ethical challenges of post-abortion care in adolescents, confidentiality was found to one of these challenges [8]. 
In autonomy-based medical ethics, it is necessary to tell the patient the facts of the disease. Indeed, there are many cultural differences in the manner of telling the truth, especially the bad news [4]. Baradin's study showed that disclosure of bad news should be based on the principles of benevolence, non-acceptance, and patient autonomy. This disclosure manner will lead to better satisfaction of patients and health care providers [9].

There is no doubt that some aspects of medical ethics have changed over the years [3]. The physician-centered approach no longer has a place in many countries, and health services are provided based on a patient-centered approach instead [4]. According to Alavizadeh, there is a positive and significant correlation between patient-centered care and health outcomes [10]. Women's decision to have a legal abortion is usually influenced by their spouse, family, society, culture, and religious beliefs. Therefore, under the title of ethical aspects of legal abortion from the viewpoint of pregnant women referring to the forensic medicine center, the present study was designed to investigate the ethical aspects of legal abortion.

\section{Materials and Methods}

The present study is a cross-sectional descriptive-analytical and aimed to investigate five ethical aspects from the pregnant women's viewpoint, referring to the Isfahan Forensic Medicine Organization for legal abortion. The data were collected from October 28, 2019, to February 20, 2020. The study was conducted in the Forensic Medicine Organization of Isfahan (one of the largest cities in Iran) on pregnant women with the gestational age of fewer than 19 weeks who had referred to forensic medicine for medical abortion permission. Using Cohen's formula for determining the sample size in quantitative studies $n=\frac{z^{2} \cdot s^{2}}{d^{2}}=\frac{1 / 96^{2} \cdot s^{2}}{0 / 13^{2}}$, the sample size was 228 subjects that, considering the probability of $10 \%$ percent drop in samples, 252 subjects were selected. The convenience sampling method was used in this study.

Inclusion criteria were the women's consent, the women who had requested a medical abortion, women with legal abortion authorization letters with specified gestational age, and Iranian nationality.

A researcher-made questionnaire was used as a data collection tool. For the evaluation of the content validity, the opinions of 20 experts, midwifery faculty members of the University, medical ethics experts, and forensic experts were used. Thirty-three questions were initially 
used. After being evaluated and reviewed by the experts mentioned above and collecting their corrective opinions, three unnecessary questions that were irrelevant to the research objectives were identified and eliminated. Necessary changes were made to increase the content validity of other questions. The questionnaire's content validity was confirmed with a CVR greater than 0.42 and a CVI of 0.79 .

To determine its reliability, the questionnaire was given to 10 women who had requested an abortion and were, evaluated. These subjects were excluded from the study. With the Cronbach's alpha coefficient above 0.7 , the reliability was calculated to be 0.742 in this study.

The questionnaire had three parts. The first part of the questionnaire included demographic information (age, occupation, education, family income, duration of marriage). The second part of the questionnaire was collecting fertility data (i.e., number of pregnancies, deliveries, and abortions, gestational age, history of infertility, wanted or unwanted pregnancies, number of alive children, number of a dead child). The third part consisted of a questionnaire about the ethical aspects of legal abortion, including five aspects (i.e., autonomy, beneficence, and non-maleficence, justice, confidentiality, and how to break bad news), which had 30 questions and was measured by 5-point Likert scale (agree strongly to disagree strongly). The scores of 1 and 5 were given to "disagree strongly" and "agree strongly," respectively. The minimum and maximum scores were 30 and 150, respectively. The questionnaire was a combination of positive and negative questions in which the scoring order was reversed for the negative questions.

After obtaining permission from the Ethics Committee of the Isfahan University of Medical Sciences and a letter of introduction from the University, the researcher referred to Isfahan forensic medicine and, after introducing herself and explaining the objectives of the research, began sampling. The convenience sampling method was used based on the inclusion criteria, and after explaining the objectives of the research and completing the informed consent form by the research subjects, the questionnaires were completed by the researcher. No information about the identity of the respondents was recorded. After data collection, they were analyzed using SPSS software version 22. Descriptive statistics (number, percentage, mean and standard deviation) and inferential statistics (Pearson correlation coefficients, Spearman correlation, and independent t-test) with a significant level of less than 0.05 (P $<0.05)$ were used. 


\section{Ethical Considerations}

The study was approved by the Ethics Committee of Isfahan University of Medical Sciences with the ethics code of IR.MUI.RESEARCH.REC.1398.406. Informed written consent was obtained from the subjects of the study. The subject of the study were assured about the confidentiality of their information. This study was conducted based on the ethics committee's standards and regulations and considering the rights of the research subjects.

\section{Results}

This study evaluated 229 mothers. The mothers' age range was between 18 and 47 years old, and the age range of their spouses was between 22 and 62. The mothers' mean age was $31.3 \pm 6$, and the mean age of their spouses was $35.29 \pm 7.1$ years. The mean duration of their marriage was also 9.23 \pm 6.04 years. Most mothers were housewives (183 subjects, $79.9 \%$ ) and their spouses were mostly self-employed (118 subjects, $51.5 \%)$. The type of pregnancy was wanted pregnancy in most cases (139 subjects, 60.7\%). Only nine women (3.9\%) had a history of infertility.

Table 1: Statistical description of the ethical aspects scores of legal abortion from the viewpoint of the mothers

\begin{tabular}{|l|c|c|c|c|}
\hline Ethical aspects of legal abortion & Mean & Sd & Minimum & Maximum \\
\hline Autonomy (9-45) & 36.20 & 3.01 & 26 & 43 \\
\hline Beneficence and non-maleficence (6-30) & 26.84 & 2.74 & 20 & 30 \\
\hline Justice (4-20) & 17.24 & 2.45 & 8 & 20 \\
\hline Confidentiality (7-35) & 28.16 & 4.63 & 7 & 35 \\
\hline How to break bad news (4-20) & 19.23 & 2.01 & 4 & 20 \\
\hline
\end{tabular}

As shown in Table 1, the highest mean score of ethical aspects, from mother's viewpoint, belonged to autonomy (36.20 \pm 3.01$)$. Confidentiality, with a mean score of (28.16 \pm 4.63$)$, was in the second rank. Beneficence and non-maleficence aspect, with the mean score of (26.84 \pm 2.74$)$, was in the third place, breaking the bad news, with the mean score of (19.23 \pm 2.01$)$, had the fourth place. The lowest mean score of ethical aspects belonged to justice, which was (17.24 \pm 2.45$)$.

Pearson correlation coefficient showed that the age of mothers and the family's income level had no significant relationship with the mean scores of legal abortion $(\mathrm{P}>0.05)$. The age of the spouse was inversely related to the score of breaking the bad news $(\mathrm{P}<0.05)$ but had no 
significant relationship with the scores of other ethical aspects of legal abortion $(\mathrm{P}>0.05)$. Similarly, the duration of marriage was inversely related to the score of justice $(\mathrm{P}<0.05)$, but had no significant relationship with the scores of other ethical aspects of legal abortion $(\mathrm{P}>0.05)$.

Spearman correlation coefficient indicated that the mothers' level of education was directly related to the mean score of confidentiality $(\mathrm{P}<0.05)$, but it had no significant relationship with the scores of other ethical aspects of legal abortion $(\mathrm{P}>0.05)$. The education level of the spouse was directly related to the mean score of beneficence $(\mathrm{P}<0.05)$; however, it had no significant relationship with the scores of other ethical aspects $(\mathrm{P}>0.05)$.

According to the independent t-test, the mean scores of legal abortion ethical aspects did not differ significantly between the housewives and working mothers $(\mathrm{P}>0.05)$. One-way analysis of variance showed that the mean scores of legal abortion ethical aspects did not differ significantly among the mothers whose husbands had different jobs ( $\mathrm{P}>0.05)$.

Table 2: Pearson correlation coefficients between the scores of legal abortion ethical aspects and the number of pregnancies, deliveries, abortions, number of alive children, number of the dead child, and recent gestational age

\begin{tabular}{|c|c|c|c|c|c|c|}
\hline \multicolumn{2}{|c|}{$\begin{array}{c}\text { Ethical aspects of legal } \\
\text { abortion }\end{array}$} & Autonomy & $\begin{array}{c}\text { Beneficence } \\
\text { and non- } \\
\text { maleficence }\end{array}$ & Justice & Confidentiality & $\begin{array}{c}\text { How to break } \\
\text { the bad news }\end{array}$ \\
\hline \multirow{2}{*}{$\begin{array}{c}\text { Number of } \\
\text { pregnancies } \\
\text { (gravidity) }\end{array}$} & $\mathrm{r}$ & 0.001 & -0.056 & 0.016 & 0.043 & -0.111 \\
\cline { 2 - 7 } & $\mathrm{p}$ & 0.99 & 0.40 & 0.80 & 0.52 & 0.09 \\
\hline $\begin{array}{c}\text { Number of deliveries } \\
\text { Number of abortions }\end{array}$ & $\mathrm{r}$ & 0.032 & -0.040 & 0.035 & -0.035 & -0.175 \\
\cline { 2 - 7 } & $\mathrm{p}$ & 0.63 & 0.54 & 0.60 & 0.60 & 0.008 \\
\cline { 2 - 7 } & $\mathrm{r}$ & -0.049 & -0.042 & -0.014 & 0.129 & 0.028 \\
\hline $\begin{array}{c}\text { Number of alive } \\
\text { children }\end{array}$ & $\mathrm{r}$ & 0.070 & -0.046 & 0.045 & -0.065 & -0.195 \\
\cline { 2 - 7 } & $\mathrm{p}$ & 0.29 & 0.49 & 0.50 & 0.33 & 0.003 \\
\hline \multirow{2}{*}{$\begin{array}{c}\text { Number of the dead } \\
\text { children }\end{array}$} & $\mathrm{r}$ & -0.104 & 0.002 & -0.002 & 0.066 & 0.25 \\
\cline { 2 - 7 } & $\mathrm{p}$ & 0.11 & 0.98 & 0.98 & 0.32 & 0.70 \\
\hline Recent gestational age & $\mathrm{r}$ & -0.042 & 0.009 & 0.058 & -0.019 & 0.070 \\
\cline { 2 - 7 } & $\mathrm{p}$ & 0.53 & 0.90 & 0.38 & 0.77 & 0.29 \\
\hline
\end{tabular}

Based on the Pearson correlation coefficient, the number of deliveries and the number of the 
alive child were inversely related to the score of breaking the bad news $(\mathrm{P}<0.05)$, but they had no significant relationship with the score of other ethical aspects of legal abortion (P> 0.05). The number of pregnancies, the number of abortions, and the number of a dead child, as well as recent gestational age, were not significantly correlated with the scores of legal abortion ethical aspects $(\mathrm{P}>0.05)$ (Table 2).

Table 3: mean scores of ethical aspects of legal abortion based on the type of pregnancy

\begin{tabular}{|c|c|c|c|c|c|c|c|}
\hline \multirow{2}{*}{$\begin{array}{c}\text { Ethical aspects of } \\
\text { legal abortion }\end{array}$} & \multicolumn{2}{|c|}{ Wanted } & \multicolumn{2}{c|}{ Unwanted } & \multicolumn{3}{c|}{ Independent t-test } \\
\cline { 2 - 8 } & Mean & Sd & Mean & Sd & $\mathrm{t}$ & $\mathrm{df}$ & $\mathrm{P}$ \\
\hline Autonomy & 36.24 & 3.01 & 36.13 & 3.03 & 0.27 & 227 & 0.78 \\
\hline $\begin{array}{c}\text { Beneficence and non- } \\
\text { maleficence }\end{array}$ & 27.02 & 2.58 & 26.57 & 2.95 & 1.23 & 227 & 0.22 \\
\hline Justice & 17.38 & 2.29 & 17.02 & 2.67 & 1.09 & 227 & 0.28 \\
\hline Confidentiality & 28.50 & 4.27 & 27.64 & 5.12 & 1.36 & 227 & 0.17 \\
\hline $\begin{array}{c}\text { How to break the bad } \\
\text { news }\end{array}$ & 19.38 & 1.36 & 19 & 2.71 & 1.24 & 227 & 0.22 \\
\hline
\end{tabular}

Independent t-test showed that the mean scores of legal abortion ethical aspects were not significantly different between mothers who have different types of wanted or unwanted pregnancy $(\mathrm{P}>0.05)$ (Table 3).

\section{Discussion}

Generally, the emotional understanding of pregnant women and respect for them seems to be essential in managing their difficult situations [4]. In the present study, the highest mean score belonged to autonomy $(36.20 \pm 3.01)$, which is consistent with the results of the study conducted by Vosough Taqi Dizaj et al. In their study, they stated that one of the strengths in providing services in the infertility center of Royan Institute is the possibility for the couples to participate in decisions if they wish [11]. According to Zareba et al. (2018), 95\% of women do not care about public opinion about abortion, which is consistent with our results [12]. In the present study, $68.6 \%$ of the participants stated that the opinion of others (neighbors, friends, relatives, etc.) had not been necessary for their decision to have a legal abortion. In the study of Molina-Mula and Gallo-Estrada, it was shown that the patient has no autonomy in deciding on treatment and self-care because of the specific nature of the nurse-patient relationship. In their study, it was concluded that the patient's passive role is 
more evident in the inpatient wards [13]. Azizi et al. showed that the lowest level of observance of patients' rights was associated with the right to choose the treatment method [14]. This result is also in line with the results of our study. This indicates that after being admitted, patients have less autonomy than before that time. Frederico et al. found four recurring factors that negatively affected young women's decision-making process about abortion. The first factor is women's lack of autonomy in deciding to terminate a pregnancy. In most women, the decision for terminating a pregnancy is made more by others (parents, family members, and sexual partners) and sometimes against their will [15]. The second factor, according to Frederico et al., is the over-influence of service providers on the decision of women about the location, methods, and legality of abortion procedures [15].

The second highest mean score belongs to the confidentiality aspect $(28.16 \pm 4.63)$. In a study conducted by Mohammadi et al. on patients' attitudes towards privacy and confidentiality in Tehran's selected hospitals, it was shown that most patients have a somewhat positive attitude towards the observation of privacy and confidentiality by physicians. Their finding was also in line with the results of our study. In their study, most patients agreed to share information with relatives or the medical team (even without the patient's permission) [16]. In the study of Zareba et al. (2018), 97\% of women informed their partners, 82\% informed their closest family members, and 32\% informed their friends about their decision [12]. In our study,

$71.9 \%$ of women believed that their family members have to be informed about their decisions and this percent was $51.8 \%$ for their intimate friends. Tariq and Hackert study argued that, according to electronic transmission and accountability of health insurance, the disclosure of health information to the spouses, parents, legal guardians, and the caregiver involved in the patient care should be allowed without the patient's formal consent [17]. Jolly et al., in their study, obtained essential themes, such as the participation of the woman in decision-making and privacy [18]. In the study of Arab et al., the highest score, from both nurses and patients, was given to the two aspects of patient confidentiality and respect for patients [19]. Chekol et al. conducted a study in Ethiopia entitled "Dimensions of patient satisfaction with comprehensive abortion care." According to them, privacy and confidentiality were the most critical factors in women's satisfaction with abortion care [20].

In the study of Mohammadi et al., the variables of age, sex, being urban and rural, education, ward and days of hospitalization did not patients' attitude [16]. There was a direct relationship between the mother's level of education and the confidentiality score in our study. This can suggest that the higher the level of mothers' education, the higher will be their awareness in 
this regard. As such, confidentiality becomes more important. Additionally, some educated mothers are working in society for whom the issue of confidentiality is essential.

Beneficence and non-maleficence aspect, with the mean of $26.84 \pm 2.74$, was the third important aspect of this study. Maarefi et al. showed that the lowest mean obtained among the codes of professional ethics in professional commitment was related to the honest explanation of the nursing errors to patients [21]. According to Andersson et al., the internet, friends, parents, and employees were the participants' familiar sources of information. There was a demand for a more detailed explanation of the abortion process in order to provide the participants with the feelings of safety and security during this process. In this study, the internet was a means of verification of the information [22]. Similarly, 27.1\% mothers of our study had used other methods such as the internet for obtaining information wh line with the results of Andersson can be due to inadequate explanation by doctors and medical staff about the methods, complications and benefits of therapeutic abortion resulting in mothers' decision-making trouble for having an abortion. In the study of Andersson et al., it was shown that all women who had an abortion because of fetal abnormalities had an academic education, but the level of education in the women whose abortion was due to unwanted pregnancy varied from primary to university [22]. In our study, there was a direct relationship between the spouse's education level and the score of beneficence $(\mathrm{P}<0.05)$. This suggests that the higher the level of education, the more will be the awareness of men and women. More attention will be put on the health of mothers and fetuses and their effective treatment.

With the mean of $19.23 \pm 2.01$, breaking the bad news was the fourth important aspect of our study. In a review study entitled "Telling bad news and its various aspects," Parsa et al. concluded that the prevailing practice in most countries is to reveal the diagnosis of incurable diseases, which has not yet been popular in Eastern countries [23]. In our study, news of the need for abortion was painful for $97.4 \%$ of mothers and $96.5 \%$ of fathers. Moreover, $97.8 \%$ of mothers believed that doctors and medical staff should be sufficiently skilled about breaking the bad news of the need for legal abortion to mothers.

There was an inverse relationship in our study between the spouse's age and the score of breaking the bad news. Similarly, the number of deliveries and the number of alive children was inversely related to the score of breaking the bad news $(\mathrm{P}<0.05)$. This means that the bad news should be disclosed more skillfully in the younger mothers, who have fewer children, and those with fewer deliveries. Additionally, based on mothers' psychological, social, and 
family circumstances, more time should be devoted to this issue.

The lowest mean in our study belonged to the aspect of justice (17.24 \pm 2.45$)$. According to Azizi et al., the right of access to facilities had the lowest score among patients' rights [14]. In the study conducted by Madeiro, discrimination, and mistreatment of medical staff was reported by 26 women, especially those with induced abortion [24]. This result is also in line with the results of our study. It was found in the study of Maarefi et al. that among the codes of professional ethics in the area of clinical services, the highest mean belonged to nondiscriminatory attention, which is not in line with our results [21].

The results of Zareba et al. (2019) showed that the environmental factors of age, education, place of residence, marital status, and the economic situation did not affect the process of decision-making [25]. According to the results of our study, the age of the mother, the job the mother and spouse, family income level, and the type of pregnancy (wanted or unwanted) had no relationship with the scores of legal abortion ethical aspects $(\mathrm{P}>0.05)$, that the results were in line with the results of the mentioned study.

\section{Conclusion}

In the present study, the highest and lowest means of ethical aspects belonged to the aspects of autonomy and justice, respectively. Given that many mothers agreed that their spouses should support their decisions, it is necessary to examine factors such as spouses, family, doctors, and society in this regard. Determining the ethical aspects (positive or negative) of legal abortion and mothers' viewpoint in this regard, can hopefully lead to the design of an appropriate program to improve the conditions governing legal abortion.

\section{Acknowledgments}

The researchers would like to express their gratitude to Isfahan's forensic staff, who cooperated in conducting this research. They also appreciate pregnant women who were licensed to have an abortion and cooperated in the study.

\section{Funding}

All costs of this project have been provided by the Vice Chancellor for Research of Isfahan University of Medical Sciences.

\section{Authors' contributions}


MV, AS and SH designed the study. GM and SH took part in data collection. MV and SH analyzed the data and prepared the manuscript. All authors read and approved the final manuscript.

\section{Availability of data and materials}

The datasets used and/or analysed during the current study are available from the corresponding author on reasonable request.

\section{Ethics approval and consent to participate}

The Ethics Committee of Isfahan University of Medical Sciences approved this study with the ethics code of IR.MUI.RESEARCH.REC.1398.406 and the number of 398231. Informed consent was obtained from the subjects of the study.

\section{Consent for publication}

Not applicable

\section{Competing interests}

The authors declare that they have no competing interests.

\section{Author details}

${ }^{1}$ Assistant Professor, Department of Midwifery and Reproductive Health, Isfahan University of Medical Sciences, Isfahan, Iran.

${ }^{2}$ General Practitioner, Isfahan Forensic Medicine, Isfahan, Iran.

${ }^{3}$ Professor of Pharmacotherapy, Isfahan Clinical Toxicology Research Center, Isfahan, Iran. ${ }^{4} \mathrm{MSc}$ student of midwifery, Isfahan University of Medical Sciences, Isfahan, Iran

\section{References}

1. Masjedi Arani A. Head of Forensic Medicine: Abortion statistics are a wake-up call for the country's health system Iran, Tehran: Islamic Repubic News Agency 2020 [Available from: https://www.irna.ir/news/83663050/.

2. Cunningham FG, Leveno K, Bloom S, Spong C, Dashe J, Hoffman B, et al. Williams Obstetrics. 25th ed. United States of America: Mc Graw-Hill; 2018. 532-55 p.

3. Taghizadeh M, Jafari Ns, Rezaei Mirqaed O, Suri M, Shams Akhtari A, Mahmoudi S, et al. Textbook of Medical Ethics. 1st ed. Iran ،Tehran: Babazadeh; 2016. 13-36 p. 
4. Larijani B. Physician and ethical considerations. 2nd ed. Iran ،Tehran: Baraye Farda; 2016. 64$420 \mathrm{p}$.

5. Rahimi Madiseh M, Ayazi Z. Ethics and professional ethics for professions and nursing, midwifery and paramedical students. 1st ed. Iran ،Tehran: Jame-e-Negar; 2015. 5-30 p.

6. Svenaeus F. Phenomenology of pregnancy and the ethics of abortion. Medicine, Health Care and Philosophy [Internet]. 2018; 21(1):[77-87 pp.]. Available from: https://doi.org/10.1007/s11019017-9786-x.

7. McCallum C, Menezes G, Reis AP. The dilemma of a practice: experiences of abortion in a public maternity hospital in the city of Salvador, Bahia. Historia, Ciencias, Saude--Manguinhos [Internet]. 2016; 23(1):[37 p.]. Available from: http://dx.doi.org/10.1590/S0104$\underline{59702016000100004 .}$

8. Zulu JM, Ali J, Hallez K, Kass N, Michelo C, Hyder AA. Ethics challenges and guidance related to research involving adolescent post-abortion care: a scoping review. Reproductive Health [Internet]. 2018; 15(1):[71 p.]. Available from: https://doi.org/10.1186/s12978-018-0515-6.

9. Badruddin S. Ethics of breaking sad news to patient by health care professionals: Pakistan perspective. J Clin Res Bioeth [Internet]. 2016; 7(01). Available from: http://dx.doi.org/10.4172/2155-9627.1000261

10. Alavizade $M$, Nasiripour A, Jadidi R. The Relationship between Patient-Centered Care and Health Outcomes in a Hospital: Tehran. Nursing Developement in Health [Internet]. 2016; 7(2):[1725 pp.]. Available from: http://ndhj.lums.ac.ir/article-1-139-fa.html.

11. Vosough Taqi Dizaj A, Ezabadi Z, Takbiri A, Baniasadi A. Infertility care in Royan Institute: a patient centeredness analysis . Payesh [Internet]. 2016; 15(3):[325-32 pp.]. Available from: http://payeshjournal.ir/article-1-180-fa.html.

12. Zaręba K, Makara-Studzińska $\mathrm{M}$, Ciebiera $\mathrm{M}$, Gierus J, Jakiel $\mathrm{G}$. Role of social and informational support while deciding on pregnancy termination for medical reasons. International Journal of Environmental Research and Public Health [Internet]. 2018; 15(12):[2854 p.]. Available from: https://doi.org/10.3390/ijerph15122854.

13. Molina-Mula J, Gallo-Estrada J. Impact of Nurse-Patient Relationship on Quality of Care and Patient Autonomy in Decision-Making. International Journal of Environmental Research and Public Health [Internet]. 2020; 17(3):[835 p.]. Available from: https://doi.org/10.3390/ijerph17030835.

14. Azizi M, Hashemipor B, Barati H, Barati M, Vakili M. The assessment of observing patients' right and its Necessity from View of Nurses in educational hospitals of Yazd, 2014. Nurse and Physician Within War [Internet]. 2016; 4(10 and 11):[36-43 pp.]. Available from: http://npwjm.ajaums.ac.ir/article-1-249-fa.html.

15. Frederico $M$, Michielsen $K$, Arnaldo $C$, Decat $P$. Factors influencing abortion decision-making processes among young women. International Journal of Environmental Research and Public Health [Internet]. 2018; 15(2):[329 p.]. Available from: https://doi.org/10.3390/ijerph15020329.

16. Mohammadi M, Dayyani Tilaki MS, Larijani B. Patients' attitudes about privacy and confidentiality in selected hospitals in Tehran. Medical Ethics and History of Medicine [Internet]. 2017; 9(6):[5-19 pp.]. Available from: http://ijme.tums.ac.ir/article-1-5887-fa.html.

17. Tariq RA, Hackert PB. Patient Confidentiality. 2019. StatPearls Publishing, Treasure Island (FL), PMID: 30137825. Available from: http://europepmc.org/books/NBK519540.

18. Jolly $\mathrm{Y}$, Aminu M, Mgawadere F, van den Broek N. "We are the ones who should make the decision"-knowledge and understanding of the rights-based approach to maternity care among women and healthcare providers. BMC Pregnancy and Childbirth [Internet]. 2019; 19(1):[1-8 pp.]. Available from: https://bmcpregnancychildbirth.biomedcentral.com/articles/10.1186/s12884-0192189-7.

19. Arab M, Hamouzadeh P, Yousefvand M, Namani F, Abdi M. Comparison of Patient-Centered Situation in Selected Hospitals Affiliated to Tehran University of Medical Sciences from the 
Viewpoint of Nurses and Patients. Journal of Hospital [Internet]. 2016; 15(3):[31-9 pp.]. Available from: http://jhosp.tums.ac.ir/article-1-5398-fa.html.

20. Chekol BM, Abdi DA, Adal TA. Dimensions of patient satisfaction with comprehensive abortion care in Addis Ababa, Ethiopia. Reproductive Health [Internet]. 2016; 13(1):[144 p.]. Available from: https://doi.org/10.1186/s12978-016-0259-0.

21. Maarefi F, Ashktorab T, Abbaszadeh A, Alavi Majd H. Investigating the viewpoints of patients regarding the compliance of codes of professional ethics by nurses at Jahrom hospitals of Medical Sciences 2013. Akhlagh-e Zisti (ie, Bioethics Journal) [Internet]. 2016; 3(10):[35-57 pp.]. Available from: https://doi.org/10.22037/.v3i10.13817.

22. Andersson I-M, Christensson K, Gemzell-Danielsson K. Experiences, feelings and thoughts of women undergoing second trimester medical termination of pregnancy. PLoS One [Internet]. 2014; 9(12):[e115957 p.]. Available from: https://doi.org/10.1371/journal.pone.0115957.

23. Parsa $M$, Bagheri A, Larijani B. Telling bad news and its various aspects. Medical Ethics and History of Medicine [Internet]. 2011; 4(6):[1-14 pp.]. Available from: http://ijme.tums.ac.ir/article-1145-fa.html.

24. Madeiro AP, Rufino AC. Maltreatment and discrimination in induced abortion care: perception of women in Teresina, State of Piauí, Brazil. Ciência \& Saúde Coletiva [Internet]. 2017; 22(8):[2771-80 pp.]. Available from: http://dx.doi.org/10.1590/1413-81232017228.04252016.

25. Zaręba K, La Rosa VL, Ciebiera M, Makara-Studzińska M, Gierus J, Jakiel G. Psychosocial Profile and Reproductive Decisions of Women Undergoing Pregnancy Termination for Medical Reasons-A Cross-Sectional Study. International Journal of Environmental Research and Public Health [Internet]. 2019; 16(18):[3413 p.]. Available from: https://doi.org/10.3390/ijerph16183413. 


\section{Supplementary Files}

This is a list of supplementary files associated with this preprint. Click to download.

- Legalabortionquestionnaire.pdf 